\title{
SAT1, a glutamine transporter, is preferentially expressed in GABAergic neurons
}

\author{
Tom Tallak Solbu1,2, Mona Bjørkmo 1,2, Paul Berghuis ${ }^{3}$, Tibor Harkany ${ }^{3,4}$ and Farrukh A. Chaudhry ${ }^{1,2 *}$ \\ 1 The Biotechnology Centre of Oslo, University of Oslo, Oslo, Norway \\ 2 The Centre for Molecular Biology and Neuroscience, Institute of Basic Medical Sciences, University of Oslo, Oslo, Norway \\ ${ }^{3}$ Division of Molecular Neurobiology, Department of Medical Biochemistry and Biophysics, Karolinska Institute, Stockholm, Sweden \\ 4 Institute of Medical Sciences, College of Life Sciences and Medicine, University of Aberdeen, Aberdeen, Scotland, UK
}

\section{Edited by:}

Enrico Mugnaini, Northwestern

University, USA

\section{Reviewed by:}

Jan Albrecht,

Polish Academy of Sciences, Poland

Tore Eid, Yale School of Medicine, USA

Arne Schousboe, University of

Copenhagen, Denmark

Enrico Mugnaini, Northwestern

University, USA

\section{*Correspondence:}

Farrukh A. Chaudhry, University of

Oslo, The Biotechnology Centre of

Oslo, P.O.Box 1125, Blindern,

$\mathrm{N}-0317$ Oslo, Norway.

e-mail:f.a.chaudhry@biotek.uio.no
Subsets of GABAergic neurons are able to maintain high frequency discharge patterns, which requires efficient replenishment of the releasable pool of GABA. Although glutamine is considered a preferred precursor of GABA, the identity of transporters involved in glutamine uptake by GABAergic neurons remains elusive. Molecular analyses revealed that SAT1 (Slc38a1) features system A characteristics with a preferential affinity for glutamine, and that SAT1 mRNA expression is associated with GABAergic neurons. By generating specific antibodies against SAT1 we show that this glutamine carrier is particularly enriched in GABAergic neurons. Cellular SAT1 distribution resembles that of GAD67, an essential GABA synthesis enzyme, suggesting that SAT1 can be involved in translocating glutamine into GABAergic neurons to facilitate inhibitory neurotransmitter generation.

Keywords: glutamate/GABA-glutamine cycle, GAD67, interneuron, neurotransmitter, parvalbumin, SIc38a1, SNAT1, system A

\section{INTRODUCTION}

Classical neurotransmission involves quantal release of a neurotransmitter captured in synaptic vesicles from presynaptic specializations and subsequent neurotransmitter action at specific postsynaptic receptors. Some neurotransmitters (monoamines and acetylcholine) or their metabolites undergo presynaptic reuptake not only in order to terminate their action but also to recycle released molecules. A substantial amount of released glutamate and GABA, the major fast transmitters, is instead translocated into perisynaptic astroglial processes (Schousboe, 2000; Danbolt, 2001; Fan et al., 2006). Thus, there is a net loss of neuronal glutamate and GABA at active synapses while their levels coincidently increase in perisynaptic astroglial cells. Given the prevalence of glutamatergic and GABAergic synapses and their contribution to generating complex neuronal network discharge patterns, maintaining the rate of signaling at these synapses requires continuous replenishment of the releasable neurotransmitter pool. Although glutamate and GABA actions were in the forefront of decade-long research due to their roles in (patho-)physiological brain functions, surprisingly little is known about the molecular mechanisms that maintain their metabolic balance, in particular their targeting towards synaptic release.

According to the prevailing hypothesis, glutamine is the major amino acid precursor for both glutamate and GABA synthesis, participating in a glutamate/GABA-glutamine cycle during which released glutamate and GABA are translocated into astroglial cells, converted into glutamine, and subsequently shuttled back to neurons to regenerate these neurotransmitters (Chaudhry et al., 2002a; Albrecht et al., 2007). This mechanistic view is supported by glutamine being preferentially metabolized to the transmitter pools of glutamate and GABA (Ward et al., 1983; Battaglioli and Martin, 1990; Sonnewald et al., 1993) in order to maintain increased neuronal activity (Szerb and O'Regan, 1985; Storm-Mathisen et al., 1986; Verderio et al., 1999; Holten and Gundersen, 2008). Furthermore, glutamine synthetase, the key enzyme catalyzing the formation of glutamine from glutamate, is localized to perisynaptic astroglial processes (Martínez-Hernandez et al., 1977), whereas phosphateactivated glutaminase (PAG) catalyzing regeneration of glutamate from glutamine is enriched in nerve terminals (Kvamme, 1983; Laake et al., 1999). However, the molecular mechanisms involved in glutamine transport into neurons remain to be elucidated.

The glutamate/GABA-glutamine cycle theory has been bolstered by the identification of the first system $\mathrm{N}$ transporter (SN1) and by the identification of a novel family of neutral amino acid transporters (SLC38) with a preference for glutamine (Chaudhry et al., 1999, 2002a). SN1 is specifically targeted to perisynaptic astroglial processes and mediates glutamine release at normal physiological conditions (Chaudhry et al., 2001; Boulland et al., 2002). Recently, a role for the homologous system A transporter SAT2 (aternatively termed SA1, SNAT2, ATA2) has been demonstrated in neurotransmitter generation (Jenstad et al., 2009): SAT2 is targeted to the somatodendritic segments of glutamatergic neurons where it also participates in sustaining retrograde signaling by glutamate. SAT2 localization complements that of SN1 and suggests concerted action of these transporters in glutamine shuttling from astroglial cells to neurons. The localization of these transporters contributes to our better understanding of the molecular architecture of this essential metabolic circuitry. However, the lack or restricted SAT2 expression in GABAergic neurons calls for significant contributions from other transporters (Jenstad et al., 2009). 
SAT1 (alternatively termed GlnT,SA2,SNAT1 and ATA1) is another member of the SLC38 family with preferential affinity for glutamine (Sugawara et al., 2000; Varoqui et al., 2000; Chaudhry et al., 2002b). In situ hybridization reveals high SAT1 transcript levels in GABAergic neurons (Chaudhry et al., 2002a). Therefore, we have investigated anatomical indices of SAT1's involvement in GABA formation. We have generated highly selective SAT1 antibodies to demonstrate that SAT1 is predominantly expressed in GABAergic neurons in many brain regions. SAT1 immunostaining in GABAergic neurons was confirmed using mice carrying green fluorescence protein (GFP) knocked into the GAD67 locus (GAD $\left.{ }^{\mathrm{gfp} /+}\right)$, the key enzyme involved in GABA formation. At the cellular level, SAT1 is mainly targeted to the plasma membrane, but the presence of additional intracellular immunolabeling colocalized with syntaxin- 6 suggests intracellular reservoirs and regulated SAT1 trafficking. Cumulatively, our data identify SAT1 as a molecular entity whose function can be imperative for sustaining glutamine uptake and GABA generation during high firing frequencies in inhibitory neurons.

\section{MATERIALS AND METHODS MATERIALS}

3,3'-diaminobenzidine (DAB), 4',6-diamidino-2-phenylindole dihydrochloride (DAPI), bovine serum albumin (BSA), fetal calf serum (FCS), sodium ethylenediamine tetraacetate (EDTA), polyD-lysine, nerve growth factor (NGF), ECM gel, phenylmethanesulfonyl fluoride (PMSF), Trizma base, Trizma $\mathrm{HCl}$, ethanolamine, hydrogen peroxide, porcine gelatine, saponin, Wisteria floribunda lectin (WFA), goat anti-rabbit (GAR) $\operatorname{IgG}(\mathrm{H}+\mathrm{L}) \mathrm{F}(\mathrm{ab})_{2}$-FITC, goat anti-goat (GAG) IgG $(\mathrm{H}+\mathrm{L}) \mathrm{F}(\mathrm{ab})_{2}$-Cy3, GAR-Cy5, mouse anti-FLAG were from Sigma-Aldrich, Norway. Biotinylated donkey anti-rabbit, streptavidin-biotinylated horseradish peroxidase complex, pGEX-3X expression vector, Sepharose 4B column were purchased from GE Healthcare. Alkaline phosphatase substrate buffer, DNAse, ammonium persulfate, isopropyl- $\beta$-D-thiogalactopyranosid (IPTG), TEMED were from Promega. Newborn calf serum (NCS), normal goat serum (NGS), Alexa-488, Alexa-555, Lipofectamine 2000, glutamine, pcDNA3.1, penicillin, streptomycin, trypsin, DMEM-GlutaMAX, OptiMEM were provided by Invitrogen. Fluoromount G: Electron Microscopy Sciences (EMS), USA. Nitrocellulose sheets $(0.22 \mu \mathrm{m})$, electrophoresis equipment: Hoefer Scientific Instruments, USA. Sodium dodecyl sulfate (SDS): Pierce, USA. pCMV-Tag1: Stratagene, Norway. Glycerol gelatine: Chemi-Teknik, Norway. Anti-parvalbumin: Swant, Switzerland. Paraformaldehyde (PFA): TAAB, UK. Affigel-15, Criterion gels: Bio-Rad, Norway. Sheep anti-rabbit IgG, particle concentrator: Dynal Biotech., Norway. PC12 cells were obtained from European Collection of Cell Cultures (ECACC), UK. Matrigel, anti-syntaxin-6: BD Biosciences, USA. Normal donkey serum, carbocyanine 3 (Cy3)-conjugated secondary antibodies raised in donkey: Jackson ImmunoResearch, PA, USA. Anti-synaptophysin: Abcam, Norway. Zeiss Axioplan 2, AxioVision Rel 4.4, LSM 5 META confocal laserscanning microscope: Zeiss, Germany.

\section{ANIMALS AND ETHICAL APPROVAL OF STUDIES}

Ten Wistar rats (180-200 g) were purchased from B \& K Universal (Sweden) and used for western blotting and immunocytochemistry. The animals were kept and handled according to European regulations and under veterinary agreement and supervision at the animal facility of the Institute of Basic Medical Sciences, University of Oslo. Sprague-Dawley rats for interneuron isolation and multiple labeling experiments were kept according to the European Communities Council Directive (86/609/EEC) and their use was approved by Stockholms Norra Djurförsöksetiska Nämnd (N26/2005 and N38/2005).

\section{PRIMARY ANTIBODIES AGAINST SAT1}

System $\mathrm{N}$ and system A transporters show high degree of amino acid sequence homology. However, they all have a long intracellular N-terminus exhibiting substantial degree of amino acid diversity (Chaudhry et al., 2002b). Computer predictions showed that the composition of amino acids in the N-terminus of SAT1 was highly antigenic (data not shown). We have therefore generated a glutathione S-transferase (GST) fusion protein containing SAT1's $\mathrm{N}$-terminus by subcloning corresponding nucleotides into a pGEX$3 \mathrm{X}$ vector in frame with a preceding GST. Expression of the fusion protein was induced in Escherichia coli by IPTG followed by purification of the fusion protein on a Sepharose $4 \mathrm{~B}$ column (Boulland et al., 2002). The GST-SAT1-N-terminal fusion protein was mixed with Freund's adjuvant (complete the first time and incomplete the subsequent times) and injected subcutaneously into rabbits. Antibodies against GST were removed by purifying the ensuing sera on a column containing affigel-15 coupled to GST. The flowthrough was subsequently run on an affigel- 15 column containing immobilized GST-SAT1-N-terminus. Affinity-purified antibodies were eluted from the column by rapidly decreasing the $\mathrm{pH}$ and then collected as described elsewhere (Boulland et al., 2002).

\section{PREPARATION OF PROTEIN EXTRACTS FROM RAT BRAIN AND CULTURED CELLS}

Animals were sacrificed by stunning and decapitation. Brains were rapidly dissected out and snap-frozen in liquid nitrogen and stored at $-80^{\circ} \mathrm{C}$ until further processing. Prior to Western blotting, tissues were thawed and homogenized in SDS solubilization buffer [10 mg/ml SDS, $1 \mathrm{mM}$ PMSF, $5 \mathrm{mM}$ EDTA and $10 \mathrm{mM}$ sodium phosphate buffer $(\mathrm{NaPi})]$. The protein concentration was measured by Lowry's assay using BSA as standard (Boulland et al., 2004). Brain extracts were mixed with SDS-sample buffer (10\% glycerol, $62.5 \mathrm{mM}$ Tris- $\mathrm{HCl}, \mathrm{pH} 6.8,2 \% \mathrm{SDS}, 0.01 \mathrm{mg} / \mathrm{ml}$ bromphenol blue) prior to electrophoretic separation.

COS cells were grown in 24 well plates in DME medium containing $10 \%$ calf serum and $1 \times$ pencillin/streptomycin. pcDNA3.1 vector either empty or containing sequences of SAT1 or SAT2 were transfected into COS cells by electroporation. After 3-4 days, transfected and untransfected COS cells were harvested by trypsin, solubilized in SDS solubilization buffer, their protein concentration measured, and their extracts solubilized in SDS-sample buffer as described above.

\section{ELECTROPHORESIS AND IMMUNOBLOTTING}

SDS-PAGE was performed as described (Boulland et al., 2002). Thirty micrograms of homogenates were loaded per lane, and run at $10 \mathrm{~V}$ for $90 \mathrm{~min}$. After separation, proteins were electroblotted $(100 \mathrm{~V}, 2 \mathrm{~h})$ onto nitrocellulose membranes. These were blocked with $1 \%(\mathrm{v} / \mathrm{w})$ porcine gelatine in phosphate buffered saline (PBS: 
$140 \mathrm{mM} \mathrm{NaCl}, 2.7 \mathrm{mM} \mathrm{KCl}, 1.5 \mathrm{mM} \mathrm{KH}_{2} \mathrm{PO}_{4}$ and $8.1 \mathrm{mMNa}_{2} \mathrm{HPO}_{4}$, $\mathrm{pH} 7.4)$, and incubated overnight with SAT1 antibodies $(0.3-1.0 \mu \mathrm{g} /$ $\mathrm{ml}$ ) in the same blocking solution. The blots were rinsed in PBS, reblocked in the blocking solution and incubated with alkaline phosphatase-conjugated secondary antibodies diluted in blocking solution. After extensive rinsing, membranes were immersed in alkaline phosphatase substrate buffer and the immunoreaction was allowed to develop. Finally, nitrocellulose membranes were rinsed with water and dried at room temperature.

\section{PERFUSION FIXATION AND IMMUNOPEROXIDASE IMMUNOSTAINING}

Animals were perfusion fixed and parasagittal sections were immunoperoxidase-stained as described (Chaudhry et al., 1998). Briefly, the animals were deeply anaesthetized by Equithesin at $2.5 \mathrm{ml} / \mathrm{kg}$ rat, and fixed by transcardial perfusion with $4 \%$ PFA and $0.05 \%$ GA in PBS. Brains were subsequently dissected out and postfixed overnight in the same fixative. Free-floating sections ( $40 \mu \mathrm{m}$ thick) were made by a microtome with a vibrating blade (Leica) and treated with $1 \mathrm{M}$ ethanolamine- $\mathrm{HCl}(\mathrm{pH} 7.4)$ and $1 \% \mathrm{H}_{2} \mathrm{O}_{2}$. Non-specific labeling was blocked by incubation with $10 \%$ NCS followed by incubation of the sections with primary antibodies $(3-10 \mu \mathrm{g} / \mathrm{ml})$ overnight at room temperature in a blocking solution containing $3 \%$ NCS (with or without Triton X-100). Following extensive rinsing in PBS, the sections were preincubated again in a blocking solution containing 3\% NCS and subsequently incubated with biotin-coupled secondary antibodies. The immunoreaction was developed with the biotin-streptavidin-peroxidase system and DAB activated by $0.1 \% \mathrm{H}_{2} \mathrm{O}_{2}$.

\section{IMMUNOFLUORESCENCE STAINING OF DIFFERENTIATED PC12 CELLS}

PC12 cells were transfected with FLAG-tagged SAT1 in a pCMVTag1 vector, using Lipofectamine 2000. Transfected cells were grown for 3 days in the presence of NGF (50-100 ng/ml) on glass coverslips coated with poly-D-lysine $(0.1 \mathrm{mg} / \mathrm{ml})$ and ECM gel $(1-1.5 \mu \mathrm{g} / \mathrm{ml})$. Subsequently, cells were immersion fixed for $30 \mathrm{~min}$ in $4 \%$ PFA in $\mathrm{NaPi}$ ( $\mathrm{pH} 7.4$ ), and then treated with $1 \mathrm{M}$ ethanolamine for $10 \mathrm{~min}$. Preincubation with a blocking solution (10\% NGS, 3\% BSA, $0.1 \%$ saponin in TBS pH 7.4) was followed by 2-4 h incubation with primary antibodies [anti-SAT1 $(1 \mu \mathrm{g} / \mathrm{ml})$, anti-FLAG (1:1000), anti-syntaxin-6 (1:200) and anti-synaptophysin 1:200)] in the same blocking solution. After extensive rinsing in PBS, immunoreactivity was revealed by fluorochromated secondary antibodies [Alexa-488 (1:1000) and Alexa-555 (1:1000)], rinsed in PBS, and mounted on glass slides using Flouromount.

\section{SAT1 LOCALIZATION IN GAD67 $7^{\mathrm{GP} /+}$ MICE AND CULTURED INTERNEURONS}

Mice heterozygously expressing GFP knocked into the GAD67 locus (GAD67 $7^{\mathrm{gfp} /+}$ ) (Tamamaki et al., 2003) were perfusion fixed (see above). Interneurons were isolated from fetal cortices of E18/19 Sprague-Dawley rat embryos. Cortices were enzymatically dissociated and interneurons were sorted immuno-magnetically as described (Berghuis et al., 2004). Immunofluorescence localization of SAT1 was performed according to published procedures both on forebrain sections and in cultured neurons (Berghuis et al., 2004). Cells were fixed in 4\% PFA in NaPi buffer (0.1 M, pH 7.4; PB) for $20 \mathrm{~min}$, rinsed in $\mathrm{PB}$, and permeabilized with $0.25 \%$ Triton $\mathrm{X}-100$ for 15 min. Blocking of aspecific labeling was achieved by applying $5 \%$ normal donkey serum and 2\% BSA in PB for $1 \mathrm{~h}$. Subsequently, the specimens were exposed to affinity-purified rabbit anti-SAT1 (1:1000), anti-PARV $(1: 2000)$ and WFA $(20 \mu \mathrm{g} / \mathrm{ml})$ in $0.1 \mathrm{M} \mathrm{PB}$ at $4^{\circ} \mathrm{C}$ overnight. Immunoreactivities were visualized with appropriate cocktails of secondary antibodies raised in donkey (1:200). Pre-absorption of the primary antibody with the corresponding fusion protein $(20 \mu \mathrm{g} / \mathrm{ml})$ in control experiments led to a complete absence of immunolabeling.

\section{RESULTS}

\section{NOVEL SAT1 ANTIBODIES ARE HIGHLY SELECTIVE}

To assess the (sub-)cellular localization of SAT1, we raised antibodies in two rabbits against its $\mathrm{N}$-terminal, the most unique and antigenic region. The specificity of antisera we have obtained is supported by selective immunostaining of electrophoretically separated extracts of COS cells transiently expressing SAT1, but not of cells transiently transfected with SAT2 or a mock vector (Figure 1A). The smear seen on blots suggests high production of heterologous SAT 1 by COS cells, as has been demonstrated for SAT2, SN1 and other transporter proteins overexpressed in this cell line (Peter et al., 1995; Boulland et al., 2002; Jenstad et al., 2009). The highest possible specificity of our antibodies was further ensured by double purification: sera were affinity-purified through an agarose column containing immobilized GST followed by an agarose column containing immobilized fusion proteins of GST and SAT1-N-terminal (see Methods). Immunoblots of electrophoretically separated total brain extracts incubated with affinity-purified antibodies reveal a broad diffuse heterogeneous band at about $50 \mathrm{kDa}$ (Figure 1B). This is in agreement with the SAT1 protein's predicted molecular weight $(53 \mathrm{kDa})$ of 485 amino acids (Chaudhry et al., 2002b). Moreover, this band resembles in appearance the bands obtained by Western blotting of rat brain extracts by affinity-purified antibodies against two homologous transporters (SN1 and SAT2) as well as other transporters (Dehnes et al., 1998; Boulland et al., 2002; Jenstad et al., 2009). No additional bands were seen by anti-SAT1-N1, while two additional slender bands of heavier molecular weight were detected by anti-SAT1-N2. To minimize bias and false-positive outcome in subsequent experiments, only data obtained with the anti-SAT1$\mathrm{N} 1$ antibody was accepted and presented in this report, unless specifically stated otherwise.

We further validated the SAT1-N1 antibody's specificity by immunocytochemistry: PC12 neuroblastoma cells were transiently transfected with SAT1 containing a FLAG-tag after the initial methionine and differentiated to attain neuron-like characteristics with NGF. Double labeling of these cells with the affinity-purified SAT1-N1 antibody and a commercial antibody against FLAG-tag using different fluorochrome conjugated secondary antibodies, showed localization of both immunoreactions in the same subset of cells and demonstrated that the protein is distributed throughout these cells, including their processes (Figure 1C). Finally, immunoperoxidase staining of parasagittal brain sections reveals similar and highly cell-specific immunostaining for SAT1 by both antibodies (Figure 2A shows data for anti-SAT1-N1). Except for a weak staining in the molecular layer of the cerebellar cortex and layer I of the piriform cortex, no immunostaining remained upon 


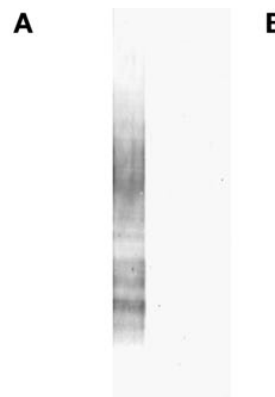

123
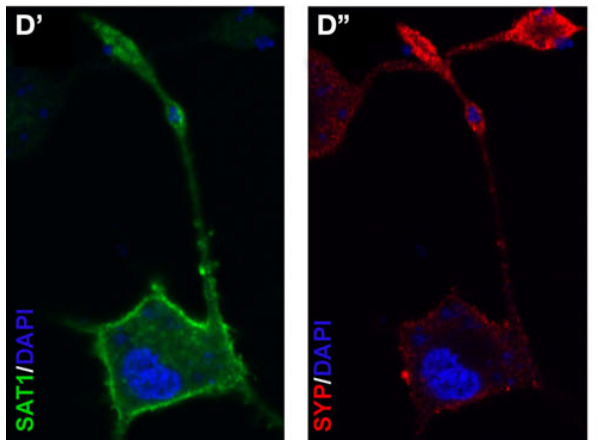

FIGURE 1 | Characterization of antibodies raised against SAT1. (A) Two rabbits were immunized with a GST fusion protein containing the N-terminus of SAT1. The sera obtained were tested for specificity by immunoblotting on extracts from COS cells transiently transfected with SAT1 (1), SAT2 (2) or a mock vector (3). Both antibodies revealed an immunoreaction restricted to extracts from SAT1 transfected cells (results shown only for anti-SAT1-N1). (B) The SAT1 selective sera were affinity purified and tested on rat brain extracts separated by SDS-PAGE. A broad band close to $50 \mathrm{kDa}$ was obtained by both antibodies (1 and 2). Two additional slender bands of higher molecular weight were detected by anti-SAT1N2 antibody (2). (C) Differentiated PC12 cells transiently transfected with FLAGtagged SAT1 were double stained with SAT1-N1 antibody (C') and a commercial
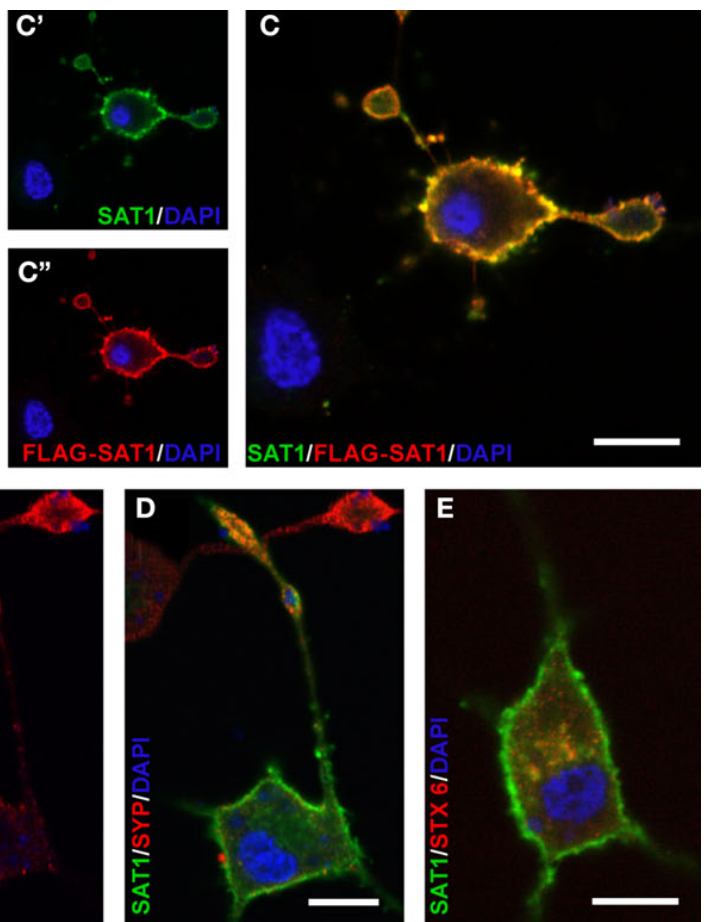

antibody against FLAG-epitope ( $\left.\mathbf{C}^{\prime \prime}\right)$. Superimposition of the images shows that both antibodies stain the same subset of PC12 cells. Note that the staining occurs in the cell bodies as well as in their processes. Note also that a cell not immunostained by anti-FLAG is not immunostained for SAT1 either. (D) SAT1 (green; $\mathbf{D}^{\prime}$ ) is targeted to the processes also labeled for synaptophysin (red; D"), a vesicular protein, demarcating axonal endings of differentiated SAT1 transfected PC12 cells. Note that an adjacent putative untransfeced cell stains strongly for synaptophysin, but eludes immunostaining by SAT1 antibody. (E) Double labeling of differentiated SAT1 transfected PC12 for SAT1 and syntaxin-6 (stx6), a marker of the trans-Golgi network, shows pronounced colocalization in the perinuclear region. All sections have been counterstained by DAPI (blue). Scale bar: $20 \mu \mathrm{m}$. preincubation of the antibodies with the GST fusion protein used to immunize rabbits (Figure 2B). Consequently, this staining was disregarded as it could be attributed to non-specific contribution of Ig-immunostaining as reported earlier (Yoshimi et al., 2002). Thus, except for these two subregions, the affinity-purified anti-SAT1-N1 antibody has passed our specificity criteria and was accepted to selectively recognize SAT1.

\section{SAT1 DISTRIBUTION RESEMBLES THAT OF GAD67 IN THE BRAIN}

To evaluate whether SAT1 may have cell type-specific functions in glutamine uptake and metabolism we investigated its cellular localization and compared its distribution with select neurotransmitter-specific markers. Survey of the parasagittal brain showed regional variations in SAT1 expression with highest levels of immunoreactivity in brainstem and cerebellum (Figure 2A). Thalamus, hypothalamus, the superior and inferior colliculi as well as the nucleus of the lateral lemniscus were prominently immunostained for SAT1 (Figure 2A). These regions harbor a large number of GABAergic neurons, i.e., cells containing GABA, its synthesizing enzyme glutamic acid decarboxylase (GAD) and/or the GABAergic neuron-specific $\mathrm{Ca}^{2+}$-binding protein parvalbu- min (PARV) (Ottersen and Storm-Mathisen, 1984; Mugnaini and Oertel, 1985; Appell and Behan, 1990; De et al., 1994). In contrast, regions rich in glutamatergic neurons, such as the cerebral cortex and the hippocampus (Ottersen and Storm-Mathisen, 1984, 1986), had much lower overall levels of SAT1 immunoreactivity (Figure 2A).

Subregional and cellular distribution of SAT1 expression was investigated by high resolution light and confocal laser-scanning microscopy. Furthermore, we explored whether SAT1 is preferentially associated to inhibitory neurons being genetically tagged in GAD67 ${ }^{\mathrm{gfp} /+}$ reporter mice (Tamamaki et al., 2003). The most pronounced immunostaining for SAT1 is concentrated in neurons of the reticular thalamic nucleus (Figures 2C,D). SAT1 co-exists with PARV and gfp in GAD67 ${ }^{\mathrm{gfp} /+}$ mice (Figures 6B,C) confirming that SAT1-positive neurons are GABAergic.

The ventral thalamic nucleus zona incerta, which is contiguous to the thalamic reticular nucleus, is rich in GAD and GABA-containing neurons that innervate thalamic nuclei (Mugnaini and Oertel, 1985; Benson et al., 1992; Bartho et al., 2002). The cells of zona incerta are also enriched in SAT1 (Figure 2A). In contrast, SAT1 immunolabeling is weaker in cells scattered across the adjacent ven- 


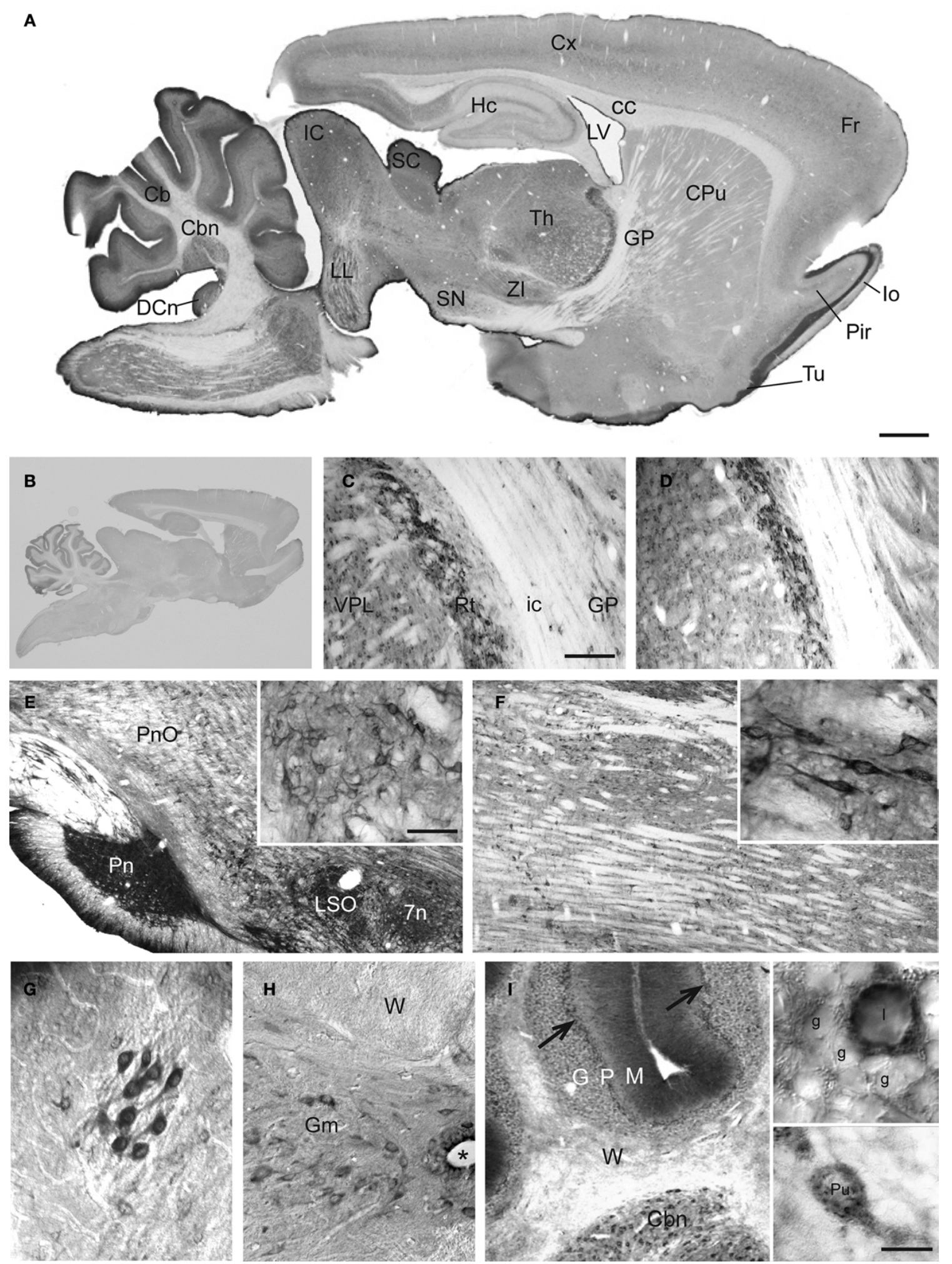

FIGURE 2 | See complete caption next page. 
FIGURE 2 | Prominent immunoperoxidase staining for SAT1 in a subset of neurons in several brain regions. (A) Immuneperoxidase staining of free-floating parasagittal brain sections reveals SAT1 localization in many subregions. The highest staining intensity is found in thalamus, mesencephalic region and cerebellum, while cortex, hippocampus and striatum over all have comparatively lower levels of staining. (B) The strong SAT1-like immunoreactivity is abolished when the antibodies are preincubated with the GST fusion protein used to immunize rabbits (result shown for anti-SAT1-N1). (C,D) Prominent cellular SAT1 immunoreactivity is detected in the reticular thalamic nucleus (Rt) by both antibodies (anti-SAT1-N1 and anti-SAT1-N2, in C and D, respectively). The ventral posterolateral thalamic nucleus (VPL) also contains scattered SAT1

immunoreactive cells although less intensely stained. Very few SAT1 immunolabeled cells are detected in the internal capsule (ic). (E) In the brain stem, SAT1 immunoreactivity is enriched in the pontine nucleus (Pn). SAT1 immunostained cells are also detected in the lateral superior olive (LSO) and facial nucleus (7n). Strongly immunostained neuron-like cells appear in the oral part of the pontine reticular nucleus $(\mathrm{PnO})$ in which SAT1 immunoreactivity is distributed in the cell body as well as their processes (inset). (F) The medulla oblongata harbors scattered neurons in the reticular formation strongly immunostained for SAT1. The inset shows some neuron-like cells enriched with strong SAT1 immunostaining distributed throughout their entire cellular extension including their processes. (G) Prominent SAT1 immunolabeling is detected in neuron-like cells in the lateral olfactory tract nucleus. $(\mathbf{H})$ In the spinal cord, moderate to strong SAT1 immunostaining is detected in neuron-like cells in the grey matter (Gm). No immunostained cell bodies are detected in the spinal white matter (W). (I) In the cerebellar granule cell layer (G), SAT1 expression is particularly prominent in some scattered neurons with large cell bodies, resembling Golgi interneurons (I), while the granule cells (g) are faintly immunolabeled (inset). Purkinje cells are also immunostained by the affinity-purified antibodies against SAT1 (arrows; lower inset). The cerebellar nuclei (Cbn) contain scattered cells strongly immunostained for SAT1. Hardly any stained cells are detected in the white matter (W). Designations: * , canalis centralis; 7n, facial nucleus; $\mathrm{Cb}$, cerebellum; Cbn, cerebellar nucleus (nucleus interpositus); cc, corpus callosum; CPu, caudate putamen; Cx, cortex; DCn, dorsal cochlear nucleus; Fr, frontal cortex; G, granule cell layer; g, granule cell; Gm, grey matter; GP, globus pallidus; Hc, hippocampus; I, interneuron; IC, inferior colliculus; lo, lateral olfactory tract; $L L$, lateral lemniscus nucleus; LSO, lateral superior olive; LV, lateral ventricle; M, molecular layer; P, Purkinje cell layer; Pir, piriform cortex; Pn, pontine nuclei; $\mathrm{PnO}$, pontine reticular nucleus, oral part; Pu, Purkinje cell; Rt, reticular thalamic nucleus; SC, superior colluculus; SN, substantia nigra; Th, thalamus; Tu, olfactory tubercule; VPL, ventral posterolateral thalamic nucleus; W, white matter; ZI, zona incerta. Scale bars: $20 \mu \mathrm{m}$ (insets I), $40 \mu \mathrm{m}$ (G, insets $\mathbf{E}$ and $\mathbf{F}$ ), $100 \mu \mathrm{m}(\mathbf{C}-\mathbf{F}, \mathbf{H}, \mathbf{I}), 350 \mu \mathrm{m}$ (A). tral posteromedial thalamic nucleus (Figures 2C,D) which do not immunostain for GAD either (Mugnaini and Oertel, 1985). Finally, barely, if any, SAT1 immunostaining was detected in the internal capsule (Figures 2B,C). This differential immunostaining of the thalamus and adjacent territories disappears upon preincubation of the affinity-purified SAT1 antibodies with their corresponding immunizing GST-SAT1 fusion protein (Figure 2B) reinforcing selective SAT1 immunostaining.

Relay neurons of the pontine nucleus participate in the corticopontocerebellar pathway, which constitutes a major excitatory input to the cerebellum (Beitz et al., 1986). The pontine nucleus itself receives extrinsic inhibitory afferents making a dense plexus of GABAergic processes and a minor number of cell bodies that also immunostain for GABA and GAD (Border and Mihailoff, 1985; Brodal et al., 1988; Feldblum et al., 1993). SAT1 expression is strong in the pontine nucleus and reveals the dense plexus of GABAergic processes in addition to cell bodies (Figure 2E). Moderate SAT1 immunoreactivity is detected in the facial nucleus (Figure 2E), another nucleus with GABAergic input from several brain stem regions. The GABAergic projections to the facial nucleus originate among other areas in the reticular formation (Vaughan, 1994; Li et al., 1997) and accordingly the pons and medulla oblongata harbor scattered neurons strongly immunostained for SAT1 (Figures 2E,F). Note that SAT1 immunostaining is enriched in the cell bodies as well as processes of these neurons (Figures 2E,F; insets). Finally, whilst principal motoneurons of the facial nucleus are primarily cholinergic in the adult rat (Yew et al., 1996), robust GAD67 expression is detected in the principal neurons of lateral superior olive (LSO) (Jenkins and Simmons, 2006). Accordingly, we find stronger immunostaining of LSO compared to facial nucleus (Figure 2E).

The cells in the nucleus of the lateral olfactory tract are strongly immunostained for SAT1 both in their cell bodies and their processes (Figure 2G). In the spinal cord, SAT1 immunoreactivity is excluded from the white matter. However, the entire grey matter (anterior and posterior horn and grey commissure) contains scattered cell bodies moderately immunostained for SAT1 (Figure 2H).
In summary, SAT1 immunoreactivity is restricted to the grey matter, and is enriched in a subset of neurons e.g. in the reticular formation and a number of nuclei in the brain stem. SAT1 immunoreactivity - in general - is most pronounced in $\mathrm{GAD}^{+}$ neurons with well-known GABAergic activity.

\section{SAT1 IS ASSOCIATED WITH GABAergic NEURONS}

To precisely evaluate SAT1 expression in GABAergic cells, we investigated broadly studied GABAergic neuron populations. In the cerebellum, SAT1 immunoreactivity occurs in Purkinje cells, the principal projection neurons (Chaudhry et al., 1998) but is undetectable in Bergmann glia ensheathing Purkinje cells (Figure 2I, lower inset). However, the strongest immunostaining for SAT1 in the cerebellum occurs in some scattered large somata cells in the granule cell layer (Figure 2I, upper inset) - an appearance and distribution consistent with Golgi cells - local GAD ${ }^{+}$ GABAergic interneurons exerting inhibitory effects on granule cells (Nusser et al., 1998; Takayama and Inoue, 2004). Despite a larger number of the cerebellar granule cells, SAT1 immunoreactivity is weak in the remaining layer (Figure 2I, upper inset). Finally, the cerebellar white matter shows insignificant immunostaining for SAT1. This corresponds with low signal intensity in the internal capsule (Figures 2C,D) and the white matter in the spinal cord (Figure 2H). SAT1's association with GABAergic neurons is also supported by immunostaining of the dorsal cochlear nucleus (Figure 2A) where cartwheel neurons share many of the characteristics of cerebellar Purkinje cells (Mugnaini et al., 1987), including the expression of not only GAD but also SAT1 (data not shown).

The globus pallidus and substantia nigra of the basal ganglia - a major cerebral system involved in regulation of motor coordination and control - contain the highest levels of GABA in the CNS (Fahn and Cote, 1968; Okada et al., 1971; Schmued et al., 1989). Some of the most pronounced cellular SAT1 expression is found in output cells of the globus pallidus (Figure 3A). High power microscopy reveals strong SAT1 immunoreactivity on the plasma membranes of their processes leaving their cytosol largely unstained (Figure 3B). 


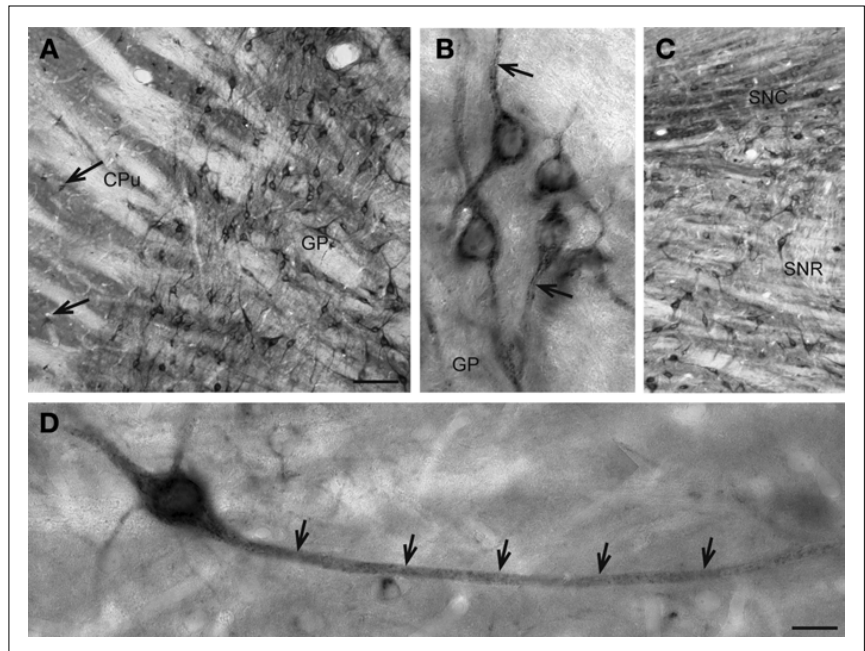

FIGURE 3 | Basal ganglionic neurons exhibit strong SAT1 immunoreactivity in their cell bodies as well as their processes.

(A) Globus pallidus (GP) is highly enriched with SAT1 immunoreactive neurons. Smaller, scattered neuron-like cells strongly immunostained for SAT1 are also detected in the caudatoputamen (CPu) (arrows). (B) High power light microscopy of neurons in the globus pallidus demonstrates SAT1 immunostaining in the cell bodies as well as in their processes. Note that the immunostaining is restricted to the plasma membrane (arrow). (C) In the reticular part of substantia nigra (SNR), neuronal cell bodies and their processes are strongly immunolabeled for SAT1. The compact part of the substantia nigra (SNC) shows SAT1 immunostaining diffusely in the neuropil and in some smaller cell bodies. (D) A neuron-like cell is stained for SAT1 in the caudatoputamen. Note that the staining appears in the cell body and its processes (arrows). CPu, caudatoputamen; GP, globus pallidus; SNC, substantia nigra pars compacta; SNR, substantia nigra pars reticulata. Scale bars: $20 \mu \mathrm{m}$ (B,D), $80 \mu \mathrm{m}$ (A,C).

These pallidal neurons show strong colocalization of SAT1, PARV and GAD in GAD67 $7^{\mathrm{gfp}+}$ mice (Figure 6B). In the substantia nigra, SAT1 immunoreactivity occurs in both its compact and reticulate parts. Cell body staining of GABAergic reticulate neurons (Figure 3C) (Ribak et al., 1976) resembles SAT1 immunostaining of cell bodies in the globus pallidus (Figures 3A,B) and colocalize with GAD67 $7^{\mathrm{gfp}+}$ (Figure 6D). In contrast, the immunostaining is diffuse in the compact part, which primarily harbors dopaminergic neurons projecting to the striatum (Figure 3C) (Tepper and Lee, 2007). The cell bodies of dopaminergic neurons are moderately SAT1 immunoreactive. Their target, the caudatoputamen, receives in addition massive glutamatergic inputs from the cortex but itself does not contain glutamatergic or dopaminergic neuronal cell bodies. Instead, the caudatoputamen harbors two subpopulations of interneurons: cholinergic large-sized and GABAergic mediumsized cells (Satoh et al., 1983; Ottersen and Storm-Mathisen, 1984). SAT1 antibodies label large-sized neurons weakly, while dispersed medium-sized neurons show strong labeling (Figure 3A; arrows). High power microscopy demonstrates that, similar to that in the pallidal neurons (Figure 3B), SAT1 immunoreactivity is enriched in medium-sized neurons' long processes (Figure 3D; arrows). Thus, our data suggest that SAT1 expression is pronounced in GABAergic neurons and that it is distributed in the cell bodies and dendritic processes. In addition to recruitment to the plasma membrane, we also observed some SAT1 immunolabeling accumulating in
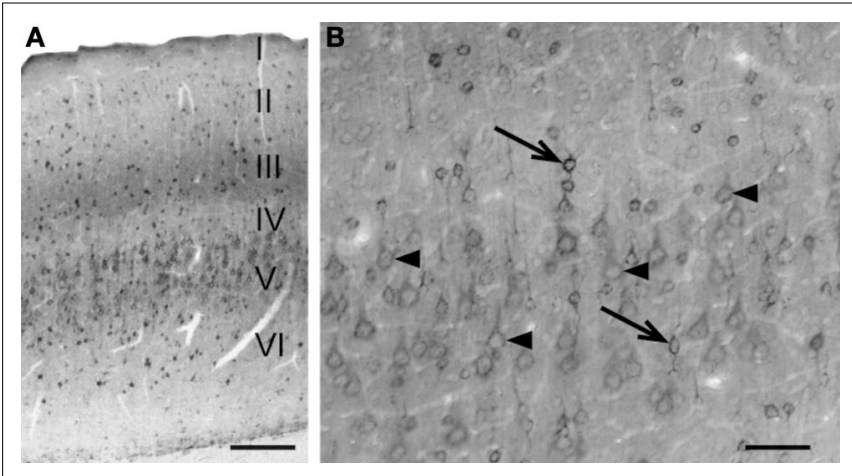

FIGURE 4 | Differential SAT1 immunoreactivity among cortical neuronal subpopulations. (A) SAT1 immunoreactive cells are detected in all layers of the neocortex. Layers III and V stand out as broad bands diffusely stained in the neuropil. (B) In the layer $V$, strong immunostaining for SAT1 is detected in scattered small neuron-like cells (arrows) while larger pyramidal-like cells (arrow heads) are moderately or weakly immunolabeled. I-VI: layers 1-VI. Scale bars: $100 \mu \mathrm{m}$ (B), $200 \mu \mathrm{m}$ (A).

the perinuclear region (e.g. in Figures 3B,D), which we judge as SAT1 in the trans-Golgi network (Bock et al., 1997) provided that syntaxin-6 colocalizes with SAT1 in transiently transfected PC12 cells (Figure 1E).

\section{PROMINENT SAT1 EXPRESSION IN NEOCORTICAL AND HIPPOCAMPAL INTERNEURONS}

In the neocortex, prominent SAT1 expression is detected in small non-pyramidal cells scattered throughout all layers and resembling interneurons (Figures 4A,B, arrows). The pyramidal-like cells are weakly immunostained (Figure 4B; arrow heads), and contribute to the band-like staining of layer III and IV (Figure 4A).

In the hippocampus (Figure 5A), strong immunostaining for SAT 1 is found in scattered cells both in cornu ammonis CA1-3 and in the dentate gyrus, while principal neurons are barely immunolabeled. The pattern of neuropil staining for SAT1, in particular in the lacunosum-moleculare resembles neuropil immunostaining seen for GABA (Ottersen and Storm-Mathisen, 1984) or GAD (Mugnaini and Oertel, 1985) in a meshwork of fibers and respective terminal populations. The hippocampal immunostaining pattern is abolished upon pre-incubation of the antibodies with a GST fusion protein containing a peptide corresponding to the SAT1 $\mathrm{N}$-terminal (Figure 5B) thus strengthening the notion that the labeling pattern we observe is genuine. Prominent immunoreactivity is seen in a subpopulation of interneuron-like cells in all layers, including stratum pyramidale (Figure 5C). Scattered interneuronlike cells with pronounced staining in their cell bodies as well as their processes are also detected in other layers, such as stratum oriens (Figure 5D).

Likewise, the granule cells of the dentate gyrus show very low SAT1 immunoreactivity (Figures 5E,F). However, scattered cells strongly immunostained for SAT1 are located in the hilus and in the basal part of the granule cell layer. These neuron-like cells project their strongly stained processes amongst weakly stained granule cells (Figure 5F). These data are in accordance with reports that cell bodies of many major interneuron subpopulations are located at the granule cell layer and hilus junction from 

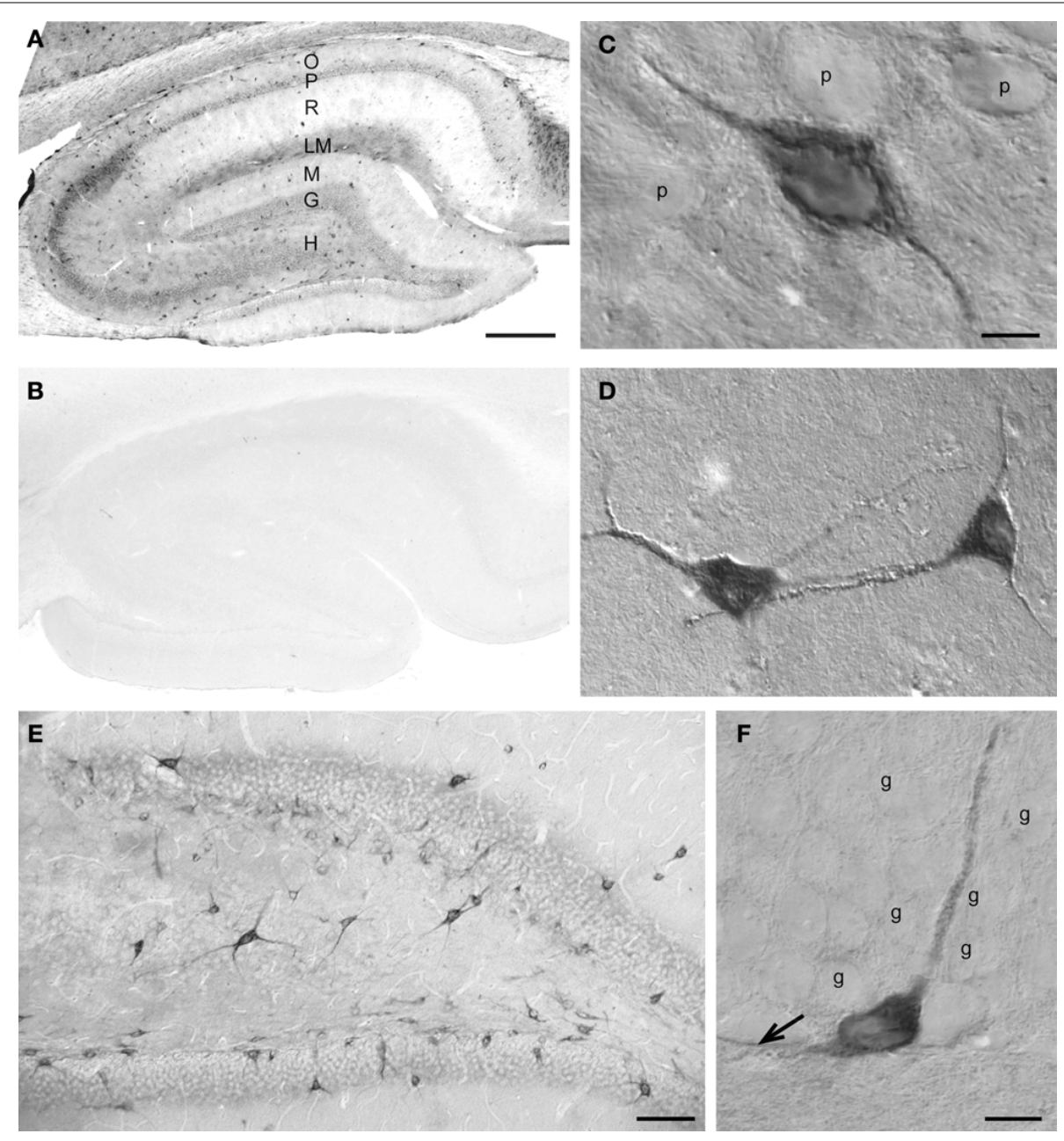

\section{FIGURE 5 | SAT1 immunostaining is enriched in hippocampal} interneurons. (A) The hippocampal formation contains dispersed cells strongly immunostained for SAT1 while the principal cells are weakly immunostained. The neuropil is moderately stained in the vicinity of the principal cells ( $P$ and $G$ ) and in stratum lacunosum-moleculare (LM). (B) SAT1 immunostaining is abolished on preincubation of SAT1 antibody with the fusion protein used for immunization. (C) High power light microscopy confirms strong SAT1 immunostaining of non-pyramidal cells and their processes between faintly labeled pyramidal cells of CA1. Intracellular stained structures are visible.

(D) Two SAT1 immunostained cells in the stratum oriens of CA1. Note that SAT1 immunoreactivity extends to the distal parts of their processes. (E) The dentate area also possesses scattered cells strongly stained for SAT1. Note their prominently SAT1 stained processes. (F) A SAT1 immunostained neuron with its cell body located in the basal part of the granule cell layer. Note that it extends a immunostained process vertically between unstained granule cells (g) and a horizontal process along the inner border of the granule cell layer (arrow). G, granule cell layer; g, granule cell; $H$, hilus; LM, stratum lacunosummoleculare; $\mathrm{M}$, stratum molecular of the area dentata; $\mathrm{O}$, stratum oriens; $\mathrm{P}$, stratum pyramidale; $p$, pyramidal cell; $R$, stratum radiatum. Scale bars: $20 \mu \mathrm{m}$ (C, D, F), $75 \mu \mathrm{m}$ (E), $150 \mu \mathrm{m}$ (A,B). where their axon ascend amongst granule cell bodies to arborize in the molecular layer (Hálasy and Somogyi, 1993), bolstering the additional SAT1 targeting in axonal segments. Indeed, SAT1 decorates processes immunostained for synaptophysin, a marker for synaptic vesicles, in differentiated PC12 cells transfected with SAT1 (Figure 1D).

In the neocortex and hippocampus SAT1 immunoreactivity colocalizes with immunostaining for PARV and GAD67 (Figure 6A). SAT1 staining also occurs in a subpopulation of GAD67 $7^{\mathrm{gfp}+}$ not immunostained for PARV supporting a role for SAT1 in a more diverse contingent of interneurons. Finally, SAT1 expression was investigated in cultured neocortical fast-spiking (FS-like) GABAergic interneurons. Both cell bodies and processes, including putative dendrites and axons, exhibited SAT1 immuno- reactivity and axonal SAT1 immunoreactivity colocalized with the vesicular GABA transporter VGAT in axonal varocosities (Figures 6E,F). Thus, SAT1 expression is pronounced in PARV ${ }^{+}$GABAergic interneurons both in vivo and in vitro, although it is not limited to this subclass of interneurons.

\section{DISCUSSION}

Functional characteristics of SAT1 are compatible with system A activity biochemically characterized several decades ago (Oxender and Christensen, 1963), including its affinity for glutamine and $\alpha$-methylamino-iso-butyric acid (MeAIB) as well as its sensitivity to $\mathrm{H}^{+}$(Sugawara et al., 2000; Varoqui et al., 2000; Chaudhry et al., 2002a). In contrast to the ubiquitous expression of SAT2, SAT1 mRNA transcript is preferentially enriched in 

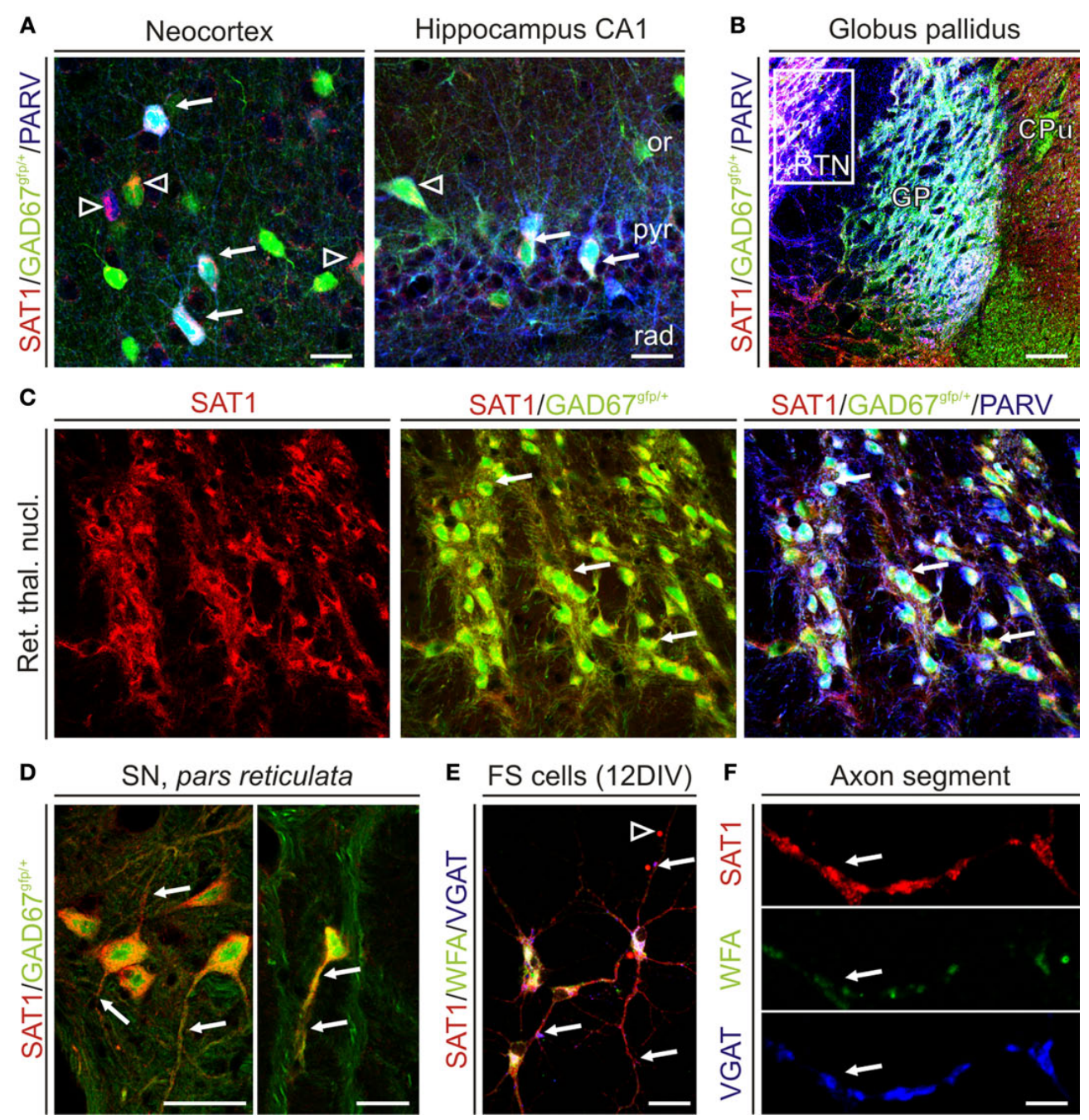

FIGURE 6 | SAT1 immunostaining is pronounced in GAD67/PARV ${ }^{+}$neurons and is targeted to VGAT containing axonal segments. Young adult mice heterozygously expressing green fluorescence protein (GFP) knocked into the GAD67 locus were perfusion fixed and immunofluorescently labeled for SAT1 and cellular markers. (A) In the neocortex (L2/3) and hippocampus, SAT1 immunoreactivity accumulates in the somatodendritic domains of a subset of GABAergic interneurons also containing PARV (arrows). Arrowheads indicate

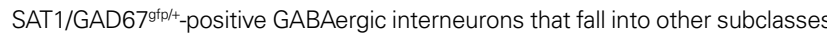
of interneurons. (B) Co-localization of SAT1 and PARV immunoreactivities in the basal ganglia. Tripled labelled neurons and their processes appear in white/light pink color. Note that virtually all PARV-containing neurons in the globus pallidus (GP) and reticular thalamic nucleus (RTN) express SAT1. Open rectangle indicates the location of images in the majority of GABAergic neurons in RTN (C). (C) Channel separation reveals co-localization of SAT1 and PARV

immunoreactivities in RTN. Arrows point to select triple-labelled cells. (D) SAT1 immunoreactive GABAergic neurons lacking PARV immunoreactivity in the substantia nigra pars reticulata. (E,F) Hippocampal PARV+ interneurons were isolated and cultured for 12 days in vitro. Considerable SAT1 immunoreactivity was only found in cells co-expressing perineuronal net components (as revealed by Wisteria floribunda lectin binding), and the vesicular GABA transporter (VGAT). Arrows point to triple-labelled varicose axonal structures. Abbreviations: $\mathrm{CPu}$, caudate putamen; GP, globus pallidus; or, stratum oriens; pyr, stratum pyramidale; rad, stratum radiatum; RTN, reticular thalamic nucleus. Scale bars $=4 \mu \mathrm{m}$ (F), $14 \mu \mathrm{m}$ (E), $30 \mu \mathrm{m}$ (A,C,D), $100 \mu \mathrm{m}$ (B). the brain, heart and placenta (Varoqui et al., 2000; Wang et al., 2000; Chaudhry et al., 2002b), suggesting isoform-specific functional roles of these transporters. We now reveal prominent SAT1 immunostaining in GABAergic neurons in many brain regions. SAT1 immunostaining extends into neuronal processes including axonal segments. SAT1 is not restricted to the plasma membrane but also appears concentrated in intracellular organelles colocalized with syntaxin-6. Thus, our data suggest highly regulated expression of SAT1 underpinning specialized cell type-specific functions.

\section{DIFFERENTIAL LOCALIZATION OF SAT1 AND SAT2 SUGGESTS ISOFORM- SPECIFIC FUNCTIONAL ROLES}

Our present findings on the distribution of SAT1 confirm previous in situ hybridization data suggesting that mRNA for SAT1 is enriched in GABAergic neurons while mRNA for SAT2 is more abundant in glutamatergic neurons (Chaudhry et al., 2002b). Indeed, SAT1 immunoreactivity correlates well with the tissue GABA concentration such that the highest staining intensities for SAT1 are found in globus pallidus and substantia nigra pars reticulata, the brain regions with the highest GABA content (Fahn and Cote, 
1968; Okada et al., 1971; Mugnaini and Oertel, 1985). Interestingly, the same brain regions are devoid of immunostaining for SAT2 (Jenstad et al., 2009). At the cellular level, SAT1 immunostaining is more prominent in GABAergic neurons while SAT2 is expressed complementary to this transporter and restricted to glutamatergic neurons: in the cerebellum, SAT1 immunolabeling is enriched in inhibitory Golgi and Purkinje neurons, while SAT2 is selectively enriched in the glutamatergic unipolar brush cells (Jenstad et al., 2009). In the neocortex and hippocampus, scattered GABAergic interneurons have high levels of SAT1 expression, while adjacent pyramidal neurons lack appreciable immunoreactivity. SAT2 exhibits an opposite cellular expression pattern in the cortex: it is barely detected in interneurons, while pyramidal neurons and hilar mossy cells, all having glutamatergic phenotypes, are SAT2 positive (Jenstad et al., 2009). In the caudatoputamen, we found strongly SAT1 immunostained medium-sized neurons surrounded by large-sized neurons with barely detectable labeling for this protein. The latter group mediate cholinergic transmission, while the former subpopulation of medium spiny neurons have previously been shown to have GABAergic phenotype and are not immunostained for SAT2 (Satoh et al., 1983; Ottersen and Storm-Mathisen, 1984; Jenstad et al., 2009). Thus, although weak immunostaining for SAT1 and its functional expression has been demonstrated in select neuronal populations also expressing SAT2 (Blot et al., 2009; Jenstad et al., 2009), SAT1 and SAT2 - in general - show surprisingly conserved complementary expression patterns in the rodent forebrain.

Our data are thus in contrast to previous studies that failed to show preferential immustaining for SAT1 in inhibitory neurons (Varoqui et al., 2000; Mackenzie et al., 2003; Weiss et al., 2003; Melone et al., 2004). In general, it has been concluded that SAT1 and SAT2 mediate the transport of amino acids for metabolic purposes (Rae et al., 2003; Conti and Melone, 2006). However, this does not exclude their roles in neurotransmitter regeneration. Indeed, SAT2 is preferentially enriched in a subpopulation of glutamatergic neurons and it has been demonstrated that SAT2-mediated glutamine transport is intrinsic to sustain specific forms of retrograde signaling (Jenstad et al., 2009).

SAT1 expression does not discriminate between short- and long-axon GABAergic neurons and also appears in cytoplasmic organelles of both, e.g., striatal and pallidal GABAergic projection neurons and cortical and hippocampal interneurons. Staining of cytoplasmic organelles was also evident in SAT1-expressing neuronally-transformed PC12 cells in which SAT1 colocalized with syntaxin-6. Similarly, homologous SAT2 has been shown in the trans-Golgi network from where it is recruited to the plasma membrane by insulin (Hatanaka et al., 2006). Adaptive regulation is a hallmark of System A and $\mathrm{N}$ transport activities (Collarini and Oxender, 1987; Palacin et al., 1998), and regulation occurs at gene, mRNA and/or protein levels (Chaudhry et al., 2001, 2002b; Hyde et al., 2002; Palii et al., 2004; Solbu et al., 2005; Grewal et al., 2009). Indeed, brain-derived neurotrophic factor specially upregulates SAT1 protein and increases glutamine uptake (Burkhalter et al., 2007).

SAT1 is not restricted to the cell bodies but is also targeted to axonal segments of GABAergic neurons: SAT1 is colocalized with VGAT in axonal varicosities in cultured $\mathrm{PARV}^{+}$hippocampal interneurons. In the intact brain, neuropil staining pattern, e.g. in the lacunosum-molecular layer of the hippocampus, suggests the association of SAT1 with GABAergic axonal plexuses. The strong and dense immunolabeling of e.g. pontine nucleus consents with staining of the plexus of GABAergic processes in addition to cell bodies. Finally, in the dentate gyrus, SAT1 immunostained processes penetrate the granule cell layer as described for local interneuron axons (Hálasy and Somogyi, 1993). Our findings thus concur with the demonstration of SAT1 being targeted to the axonal segments of cultured hippocampal neurons (Armano et al., 2002). In analogy, SAT2 is also observed on axonal segments, such as hippocampal mossy fibers in CA3 (Jenstad et al., 2009). Collectively, our data suggest that SAT1 immunostaining is partially complementary to SAT2 and specifically enriched in subpopulations of GABAergic neurons, and that SAT1 expression is highly regulated.

\section{SAT1 MAY PROVIDE GABAergic NEURONS WITH GLUTAMINE TO GENERATE GABA}

Previous reports have shown that GABAergic nerve endings in cerebellar (Holten and Gundersen, 2008) or hippocampal (StormMathisen et al., 1986) slices can maintain GABA levels through a glutaminase reaction. This is also consistent with studies in primary cortical neuron cultures as well as in synaptosomes showing that addition of glutamine increases GABA formation by several folds (Ward et al., 1983; Yu et al., 1984; Battaglioli and Martin, 1990; Schousboe et al., 1993).

GABAergic neurons often exhibit higher prevailing firing frequency (Freund and Buzsaki, 1996; Pan and McNaughton, 2004), and sustained synaptic transmission requires efficient replenishment of GABA transmitter pools. Nerve terminals concentrate GABA transporters (Ribak et al., 1996) to achieve sufficient reuptake of GABA that can be reused in synaptic transmission (Fan et al., 2006). There is also evidence that glutamine is not the only source of glutamate for GABA formation (Paulsen and Fonnum, 1988; Patel et al., 2001). However, glutamine contributes substantially to the vesicular pool of GABA as well as the cytoplasmic pool (Waagepetersen et al., 2001). Accordingly, we find strong immunolabling for SAT1 both in the cell body and in the processes, and the staining pattern resembles GAD (Mugnaini and Oertel, 1985), suggesting that SAT1 provides a precursor to cell compartments capable of GABA synthesis. Finally, mice genetically inactivated for nerve terminal GABA uptake survive and maintain vesicular GABA content (Jensen et al., 2003) indicating that alternative mechanisms or precursors must exist to replenish GABA pools, including glia-derived glutamine. Our current data are well suited to support the concept of GABA-glutamine recycling through conversion to glutamine in glia followed by transport to neurons by the concerted action of SN1/SN2 and SAT1. The data thus support previous demonstrations of glutamine being a preferred precursor for GABA synthesis (Reubi et al., 1978; Paulsen et al., 1988; Battaglioli and Martin, 1990; Martin and Rimvall, 1993; Sonnewald et al., 1993). As disruption of neuronal glutamine uptake by MeAIB reduces inhibitory synaptic transmission, System A mediated glutamine activity is important for dynamic sustainance of intracellular pool of GABA (Fricke et al., 2007). Moreover, selective enrichment of SAT1 in GABAergic neurons suggests that SAT1 may be the main transporter involved in glutamine uptake for GABA generation. However, recycling of GABA may not be restricted to SAT1 or glutamine. Additional transporters and/or alternative mechanisms may also exist to fine-tune this essential process. Although less efficiently, 
SAT1 can also transport several other neutral amino acids, including alanine, and thus may mediate transport of both glutamine and these amino acids for metabolic purposes.

\section{ACKNOWLEDGMENTS}

We are greatful to Yuchio Yanagawa for $(\Delta$ neo $)$ GAD67 $7^{\text {gfp/ } /+}$ mice and Sara M. Shah for the FLAG-SAT1 construct. We thank Professor Jon Storm-Mathisen, Dr. Misha Zilberter and Dr.

\section{REFERENCES}

Albrecht,J.,Sonnewald, U., Waagepetersen, H. S., and Schousboe, A. (2007). Glutamine in the central nervous system: function and dysfunction. Front. Biosci. 12, 332-343. doi: 10.2741/2067.

Appell,P.P., and Behan, M. (1990). Sources of subcortical GABAergic projections to the superior colliculus in the cat. J. Comp. Neurol. 302, 143-158.

Armano, S., Coco, S., Bacci, A., Pravettoni, E., Schenk, U., Verderio, C., Varoqui, H., Erickson, J.D., and Matteoli, M. (2002). Localization and functional relevance of system a neutral amino acid transporters in cultured hippocampal neurons. J. Biol. Chem. 277, 10467-10473.

Bartho, P., Freund, T. F., and Acsady, L. (2002). Selective GABAergic innervation of thalamic nuclei from zona incerta. Eur. J. Neurosci. 16, 999-1014.

Battaglioli, G., and Martin, D. L. (1990). Stimulation of synaptosomal gammaaminobutyric acid synthesis by glutamate and glutamine. J. Neurochem. 54, 1179-1187.

Beitz, A. J., Larson, A. A., Monaghan, P., Altschuler, R. A., Mullett, M. M., and Madl, J. E. (1986). Immunohistochemical localization of gltamate, glutaminase and aspartate aminotransferase in neurons of the pontine nuclei of the rat. Neuroscience 17, 741-753.

Benson, D. L., Isackson, P. J., Gall, C. M., and Jones, E. G. (1992). Contrasting patterns in the localization of glutamic acid decarboxylase and $\mathrm{Ca} 2+/$ calmodulin protein kinase gene expression in the rat central nervous system. Neuroscience 46, 825-849.

Berghuis, P., Dobszay, M. B., Sousa, K. M., Schulte, G., Mager, P. P., Hartig, W., Gorcs, T. J., Zilberter, Y., Ernfors, P., and Harkany, T. (2004). Brain-derived neurotrophic factor controls functional differentiation and microcircuit formation of selectively isolated fastspiking GABAergic interneurons. Eur. J. Neurosci. 20, 1290-1306.

Blot, A., Billups, D., Bjorkmo, M., Quazi, A. Z., Uwechue, N. M., Chaudhry, F. A., and Billups, B. (2009). Functional expression of two system A glutamine transporter isoforms in rat auditory brainstem neurons. Neuroscience 164, 998-1008.

Bock, J. B., Klumperman, J., Davanger, S., and Scheller, R. H. (1997). Syntaxin 6 functions in trans-Golgi network vesicle trafficking. Mol. Biol. Cell 8, 1261-1271.

Border, B. G., and Mihailoff, G. A. (1985). GAD-immunoreactive neural elements in the basilar pontine nuclei and nucleus reticularis tegmenti pontis of the rat. I. Light microscopic studies. Exp. Brain Res. 59, 600-614.

Boulland, J. L., Osen, K. K., Levy, L. M., Danbolt, N. C., Edwards, R. H., Storm-Mathisen, J., and Chaudhry, F. A. (2002). Cell-specific expression of the glutamine transporter SN1 suggests differences in dependence on the glutamine cycle. Eur. J. Neurosci. 15, 1615-1631.

Boulland, J. L., Qureshi, T., Seal, R. P., Rafiki, A., Gundersen, V., Bergersen, L. H., Fremeau, R. T. Jr., Edwards, R. H., Storm-Mathisen, J., and Chaudhry, F. A. (2004). Expression of the vesicular glutamate transporters during development indicates the widespread corelease of multiple neurotransmitters. J. Comp. Neurol. 480, 264-280.

Brodal, P., Mihailoff, G., Border, B., Ottersen, O. P., and Storm-Mathisen, J. (1988). GABA-containing neurons in the pontine nuclei of rat, cat and monkey. An immunocytochemical study (published erratum appears in Neuroscience 1988 Aug; 26(2):725). Neuroscience 25, 27-45.

Burkhalter, J., Fiumelli, H., Erickson, J. D., for system A amino acid transport in the regulation of dendritic development by brain-derived neurotrophic factor (BDNF). J. Biol. Chem. 282, 5152-5159.

Chaudhry, F. A., Krizaj, D., Larsen, P., Reimer, R. J., Storm-Mathisen, J., Copenhagen, D. R., Kavanaugh, M. P., and Edwards, R. H. (2001). Coupled and uncoupled proton movement regulates amino acid transport by System N. EMBO J. 20, 7041-7051.

Chaudhry, F. A., Reimer, R. J., Bellocchio, E. E., Danbolt, N. C., Osen, K. K., Edwards, R. H., and Storm-Mathisen, J. (1998). The vesicular GABA transporter, VGAT, localizes to synaptic and Martin, J. L. (2007). A critical role

Vidar Gundersen for constructive discussions and for revision of the manuscript. This work was supported by the Research Council of Norway [RCN; Young Investigator Award (Farrukh A. Chaudhry)], the Steering Board of Life Sciences at the University of Oslo (EMBIO; Tom Tallak Solbu and Mona Bjørkmo), the European Commission (HEALTH-F2-201159; Tibor Harkany), the Alzheimer's Association (Tibor Harkany), and the NIH (DA023214, Tibor Harkany).

vesicles in sets of glycingergic as well as GABAergic neurons. J. Neurosci. 18 , 9733-9750.

Chaudhry, F. A., Reimer, R. J., and Edwards, R.H.(2002a). The glutamine commute: take the $\mathrm{N}$ line and transfer to the A. J. Cell Biol. 157, 349-355.

Chaudhry, F. A., Schmitz, D., Reimer, R. J., Larsson, P., Gray, A. T., Nicoll, R., Kavanaugh, M., and Edwards, R. H. (2002b). Glutamine uptake by neurons: interaction of protons with system a transporters. J. Neurosci. 22, 62-72.

Chaudhry, F. A., Reimer, R. J., Krizaj, D., Barber, R., Storm-Mathisen, J., Copenhagen, D. R., and Edwards, R.H. (1999). Molecular analysis of System $\mathrm{N}$ suggests novel physiological roles in nitrogen metabolism and synaptic transmission. Cell 99, 769-780.

Collarini, E. J., and Oxender, D. L. (1987) Mechanisms of transport of amino acids across membranes. Annu. Rev. Nutr. 7, 75-90.

Conti, F., and Melone, M. (2006). The glutamine commute: lost in the tube? Neurochem. Int. 48, 459-464.

Danbolt, N.C. (2001). Glutamate uptake. Prog. Neurobiol. 65, 1-105.

De, B. S., Arcelli, P., and Spreafico, R. (1994). Parvalbumin immunoreactivity in the thalamus of guinea pig: light and electron microscopic correlation with gamma-aminobutyric acid immunoreactivity. J. Comp. Neurol. 348, 556-569.

Dehnes, Y., Chaudhry, F. A., Ullensvang K., Lehre, K. P., Storm-Mathisen, J., and Danbolt, N. C. (1998). The glutamate transporter EAAT4 in rat cerebellar Purkinje cells: a glutamate-gated chloride channel concentrated near the synapse in parts of the dendritic membrane facing astroglia. J. Neurosci. 18, 3606-3619.

Fahn, S., and Cote, L. J. (1968). Regional distribution of gamma-aminobutyric acid (GABA) in brain of the rhesus monkey. J. Neurochem. 15, 209-213.

Fan, H. P., Fan, F. J., Bao, L., and Pei, G. (2006). SNAP-25/syntaxin 1A complex functionally modulates neurotransmitter gamma-aminobutyric acid reuptake. J. Biol. Chem. 281, 28174-28184.

Feldblum, S., Erlander, M. G., and Tobin, A. J. (1993). Different distributions of
GAD65 and GAD67 mRNAs suggest that the two glutamate decarboxylases play distinctive functional roles. $J$. Neurosci. Res. 34, 689-706.

Freund, T. F., and Buzsaki, G. (1996). Interneurons of the hippocampus. Hippocampus 6, 347-470.

Fricke, M. N., Jones-Davis, D. M., and Mathews, G. C. (2007). Glutamine uptake by System A transporters maintains neurotransmitter GABA synthesis and inhibitory synaptic transmission. J. Neurochem. 102, 1895-1904.

Grewal, S., Defamie, N., Zhang, X., De, G. S., Shawki, A., Mackenzie, B., Chen, C., Varoqui, H., and Erickson, J. D. (2009). SNAT2 amino acid transporter is regulated by amino acids of the SLC6 gamma-aminobutyric acid transporter subfamily in neocortical neurons and may play no role in delivering glutamine for glutamatergic transmission. J. Biol. Chem. 284, 11224-11236.

Hálasy, K., and Somogyi, P. (1993). Subdivisions in the multiple GABAergic innervation of granule cells in the dentate gyrus of the rat hippocampus. Eur. J. Neurosci. 5, 411-429.

Hatanaka, T., Hatanaka, Y., Tsuchida, J., Ganapathy, V., and Setou, M. (2006). Amino acid transporter ATA2 is stored at the trans-Golgi network and released by insulin stimulus in adipocytes. J. Biol. Chem. 281, 39273-39284.

Holten, A. T., and Gundersen, V. (2008). Glutamine as a precursor for transmitter glutamate, aspartate and GABA in the cerebellum: a role for phosphate-activated glutaminase. $J$. Neurochem. 104, 1032-1042.

Hyde, R., Peyrollier, K., and Hundal, H. S. (2002). Insulin promotes the cell surface recruitment of the SAT2/ATA2 system A amino acid transporter from an endosomal compartment in skeletal muscle cells. J. Biol. Chem. 277, 13628-13634.

Jenkins, S.A., and Simmons, D. D. (2006). GABAergic neurons in the lateral superior olive of the hamster are distinguished by differential expression of gad isoforms during development. Brain Res. 1111, 12-25. 
Jensen, K., Chiu, C. S., Sokolova, I., Lester, H. A., and Mody, I. (2003). GABA transporter-1 (GAT1)-deficient mice: differential tonic activation of GABAA versus GABAB receptors in the hippocampus. J. Neurophysiol. 90 , 2690-2701.

Jenstad, M., Quazi, A. Z., Zilberter, M., Haglerod, C., Berghuis, P., Saddique, N., Goiny, M., Buntup, D., Davanger, S., Haug, F. M. S., Barnes, C. A., McNaughton, B. L., Ottersen, O. P., Storm-Mathisen, J., Harkany, T., and Chaudhry, F. A. (2009). System A transporter SAT2 mediates replenishment of dendritic glutamate pools controlling retrograde signaling by glutamate. Cereb. Cortex 19, 1092-1106.

Kvamme, E. (1983). Glutaminase (PAG). Neurol. Neurobiol. 7, 51-67.

Laake, J. H., Takumi, Y., Eidet, J., Torgner, I. A., Roberg, B., Kvamme, E., and Ottersen, O.P. (1999). Postembedding immunogold labelling reveals subcellular localization and pathway-specific enrichment of phosphate activated glutaminase in rat cerebellum. Neuroscience 88, 1137-1151.

Li, Y. Q., Takada, M., Kaneko, T., and Mizuno, N. (1997). Distribution of GABAergic and glycinergic premotor neurons projecting to the facial and hypoglossal nuclei in the rat. J. Comp. Neurol. 378, 283-294.

Mackenzie, B., Schafer, M. K., Erickson, J. D., Hediger, M. A., Weihe, E., and Varoqui, H. (2003). Functional properties and cellular distribution of the system A glutamine transporter SNAT1 support specialized roles in central neurons. J. Biol. Chem. 278, 23720-23730.

Martin, D. L., and Rimvall, K. (1993). Regulation of gamma-aminobutyric acid synthesis in the brain. $J$. Neurochem. 60, 395-407.

Martínez-Hernandez, A., Bell, K. P., and Norenberg, M. D. (1977). Glutamine synthetase: glial localization in brain. Science 195, 1356-1358.

Melone, M., Quagliano, F., Barbaresi, P., Varoqui, H., Erickson, J. D., and Conti, F. (2004). Localization of the glutamine transporter SNAT1 in rat cerebral cortex and neighboring structures, with a note on its localization in human cortex. Cereb. Cortex 14, 562-574.

Mugnaini, E., Berrebi, A. S., Dahl, A. L., and Morgan, J. I. (1987). The polypeptide PEP-19 is a marker for Purkinje neurons in cerebellar cortex and cartwheel neurons in the dorsal cochlear nucleus. Arch. Ital. Biol. 126, 41-67.

Mugnaini, E., and Oertel, W. H. (1985). An atlas of the distribution of GABAergic neurons and terminals in the rat CNS as revealed by GAD immunohistochemistry. In Handbook of Chemical Neuroanatomy, Vol. 4, A. Björklund, T. Hökfelt, eds (Amsterdam, Elsevier Science Publishers), pp. 436-608.

Nusser, Z., Sieghart, W., and Somogyi, P. (1998). Segregation of different GABAA receptors to synaptic and extrasynaptic membranes of cerebellar granule cells. J. Neurosci. 18, 1693-1703.

Okada, Y., Nitsch-Hassler, C., Kim, J. S., Bak, I. J., and Hassler, R. (1971). Role of -aminobutyric acid (GABA) in the extrapyramidal motor system. 1. Regional distribution of GABA in rabbit, rat, guinea pig and baboon CNS. Exp. Brain Res. 13, 514-518.

Ottersen, O. P., and Storm-Mathisen, J. (1984). Glutamate-and GABAcontaining neurons in the mouse and rat brain as demonstrated with a new immunocytochemical technique. J. Comp. Neurol. 229, 374-392.

Ottersen, O. P., and Storm-Mathisen, J. (1986). Excitatory amino acid pathways in the brain. Adv. Exp. Med. Biol. 203, 263-284.

Oxender, D. L., and Christensen, H. N. (1963). Distinct mediating systems for the transport of neutral amino acids by the Ehrlich cell. J. Biol. Chem. 238, 3686-3699.

Palacin, M., Estevez, R., Bertran, J., and Zorzano, A. (1998). Molecular biology of mammalian plasma membrane amino acid transporters. Physiol. Rev. 78, 969-1054.

Palii, S. S., Chen, H., and Kilberg, M. S. (2004). Transcriptional control of the human sodium-coupled neutral amino acid transporter system $A$ gene by amino acid availability is mediated by an intronic element. J. Biol. Chem. 279, 3463-3471.

Pan, W. X., and McNaughton, N. (2004). The supramammillary area: its organization, functions and relationship to the hippocampus. Prog. Neurobiol. 74, 127-166.

Patel, A. B., Rothman, D. L., Cline, G. W., and Behar, K. L. (2001). Glutamine is the major precursor for GABA synthesis in rat neocortex in vivo following acute GABA-transaminase inhibition. Brain Res. 919, 207-220.

Paulsen, R. E., and Fonnum, F. (1988). Regulation of transmitter gammaaminobutyric acid (GABA) synthesis and metabolism illustrated by the effect of ()-vinyl (GABA) and hypoglycemia. J. Neurochem. 50, 1151-1157.

Paulsen, R. E., Odden, E., and Fonnum, F. (1988). Importance of glutamine for gamma-aminobutyric acid synthesis in rat neostriatum in vivo. J. Neurochem. 13, 637-641.

Peter, D., Liu, Y., Sternini, C., de Giorgio, R., Brecha, N., and Edwards, R. H.
(1995). Differential expression of two vesicular monoamine transporters. J. Neurosci. 15, 6179-6188.

Rae, C., Hare, N., Bubb, W. A., McEwan, S. R., Broer, A., McQuillan, J. A., Balcar, V. J., Conigrave, A. D., and Broer, S. (2003). Inhibition of glutamine transport depletes glutamate and GABA neurotransmitter pools: further evidence for metabolic compartmentation. J. Neurochem. 85, 503-514.

Reubi, J. C., Van den Berg, C. J., and Cuénod, M. (1978). Glutamine as a precursor for the GABA and glutamate transmitter pools. Neuroscience $10,171-174$.

Ribak, C. E., Tong, W. M., and Brecha, N. C. (1996). GABA plasma membrane transporters, GAT-1 and GAT-3, display different distributions in the rat hippocampus. J. Comp. Neurol. 367, 595-606.

Ribak, C. E., Vaughn, J. E., Saito, K., Barber, R., and Roberts, E. (1976). Immunocytochemical localization of glutamate decarboxylase in rat substantia nigra. Brain Res. 116, 287-298.

Satoh, K., Staines, W. A., Atmadja, S., and Fibiger, H. C. (1983). Ultrastructural observations of the cholinergic neuron in the rat striatum as identified by acetylcholinesterase pharmacohistochemistry. Neuroscience 10, 1121-1136.

Schmued, L., Phermsangngam, P., Lee, H., Thio, S., Chen, E., Truong, P., Colton, E., and Fallon, J. (1989). Collateralization and GAD immunoreactivity of descending pallidal efferents. Brain Res. 487, 131-142.

Schousboe, A. (2000). Pharmacological and functional characterization of astrocytic GABA transport: a short review. Neurochem. Res. 25, 1241-1244.

Schousboe, A., Westergaard, N., and Hertz, L. (1993). Neuronal-astrocytic interactions in glutamate metabolism. Biochem. Soc. Trans. 21, 49-53.

Solbu, T. T., Boulland, J. L., Zahid, W., Lyamouri Bredahl, M. K., miryMoghaddam, M., Storm-Mathisen, J., Roberg, B. A., and Chaudhry, F. A. (2005). Induction and targeting of the glutamine transporter SN1 to the basolateral membranes of cortical kidney tubule cells during chronic metabolic acidosis suggest a role in $\mathrm{pH}$ regulation. J. Am. Soc. Nephrol. $16,869-877$.

Sonnewald, U., Westergaard, N., Schousboe, A., Svendsen, J.S., Unsgard, G., and Petersen, S. B. (1993). Direct demonstration by [13C]NMR spectroscopy that glutamine from astrocytes is a precursor for GABA synthesis in neurons. Neurochem. Int. 22, 19-29.
Storm-Mathisen, J., Ottersen, O. P., Fulong, T., Gundersen, V., Laake, J. H. and Nordbø, G. (1986). Metabolism and transport of amino acids studied by immunocytochemistry. Med. Biol. 64, 127-132.

Sugawara, M., Nakanishi, T., Fei, Y. J., Huang, W., Ganapathy, M. E., Leibach, F. H., and Ganapathy, V. (2000). Cloning of an amino acid transporter with functional characteristics and tissue expression pattern identical to that of system A. J. Biol. Chem. 275, 16473-16477.

Szerb, J. C., and O’Regan, P. A. (1985). Effect of glutamine on glutamate release from hippocampal slices induced by high $\mathrm{K}+$ or by electrical stimulation: Interaction with different $\mathrm{Ca} 2+$ concentrations. J. Neurochem. 44, 1724-1731.

Takayama, C., and Inoue, Y. (2004). Morphological development and maturation of the GABAergic synapses in the mouse cerebellar granular layer. Brain Res. Dev. Brain Res. 150, 177-190.

Tamamaki, N., Yanagawa, Y., Tomioka, R., Miyazaki, J., Obata, K., and Kaneko, T. (2003). Green fluorescent protein expression and colocalization with calretinin, parvalbumin, and somatostatin in the GAD67-GFP knock-in mouse. J. Comp. Neurol. 467, 60-79.

Tepper, J. M., and Lee, C. R. (2007). GABAergic control of substantia nigra dopaminergic neurons. Prog. Brain Res. 160, 189-208.

Varoqui, H., Zhu, H., Yao, D., Ming, H., and Erickson, J.D. (2000). Cloning and functional identification of a neuronal glutamine transporter. J. Biol. Chem. 275, 4049-4054.

Vaughan, D. W. (1994). Effects of peripheral axotomy on presynaptic axon terminals with GABA-like immunoreactivity. Anat. Rec. 238, 248-262.

Verderio, C., Bacci,A., Coco, S., Pravettoni, E., Fumagalli, G., and Matteoli, M. (1999). Astrocytes are required for the oscillatory activity in cultured hippocampal neurons. Eur. J. Neurosci. 11, 2793-2800.

Waagepetersen, H. S., Sonnewald, U., Gegelashvili, G., Larsson, O. M., and Schousboe, A. (2001). Metabolic distinction between vesicular and cytosolic GABA in cultured GABAergic neurons using $13 \mathrm{C}$ magnetic resonance spectroscopy. J. Neurosci. Res. 63, 347-355.

Wang, H., Huang, W., Sugawara, M., Devoe, L. D., Leibach, F. H., Prasad, P. D., and Ganapathy, V. (2000). Cloning and functional expression of ATA1, a subtype of amino acid transporter A, from human placenta. Biochem. Biophys. Res. Commun. 273, 1175-1179. 
Ward, H. K., Thanki, C. M., and Bradford, H. F. (1983). Glutamine and glucose as precursors of transmitter amino acids: ex vivo studies. J. Neurochem. 40, 855-860.

Weiss, M. D., Derazi, S., Rossignol, C., Varoqui, H., Erickson, J.D., Kilberg, M. S., and Anderson, K. J. (2003). Ontogeny of the neutral amino acid transporter SAT1/ATA1 in rat brain. Brain Res. Dev. Brain Res. 143, 151-159.

Yew, D. T., Webb, S. E., and Lam, E. T. (1996). Neurotransmitters and pep- tides in the developing human facial nucleus. Neurosci. Lett. 206, 65-68.

Yoshimi, K., Woo, M., Son, Y., Baudry, M., and Thompson, R. F. (2002). IgG-immunostaining in the intact rabbit brain: variable but significant staining of hippocampal and cerebellar neurons with anti-IgG. Brain Res. 956, 53-66.

Yu, A. C., Fisher, T. E., Hertz, E., Tildon, J. T., Schousboe, A., and Hertz, L. (1984). Metabolic fate of [14C]-glutamine in mouse cerebral neurons in primary cultures. J. Neurosci. Res. 11, 351-357.

Conflict of Interest Statement: The authors declare that the research was conducted in the absence of any commercial or financial relationships that could be construed as a potential conflict of interest.

Received:07 December 2009; paperpending published: 21 December 2009; accepted: 30 December 2009; published online: 08 February 2010.
Citation: Solbu TT, Bjørkmo M, Berghuis P, Harkany Tand Chaudhry FA (2010) SAT1, a glutamine transporter, is preferentially expressed in GABAergicneurons. Front. Neuroanat. 4:1. doi: 10.3389/neuro.05.001.2010 Copyright (C) 2010 Solbu, Bjørkmo, Berghuis, Harkany and Chaudhry. This is an open-access article subject to an exclusive license agreement between the authors and the Frontiers Research Foundation, which permits unrestricted use, distribution, and reproduction in any medium, provided the original authors and source are credited. 